\title{
Production and people values: their impact on relationships and leader effectiveness in China
}

\author{
Chun-hong Liu \\ Associate Professor, School of Business and Management, Dong Hua University, \\ Shanghai, China \\ Zi-you Yu \\ Associate Professor, Department of Management, Lingnan University, Hong Kong \\ Dean Tjosvold \\ Professor, Department of Management, Lingnan University, Hong Kong
}

\section{Keywords}

Leadership, Effectiveness,

Productivity, Employees

\section{Abstract}

Productivity and people maintenance values have traditionally been considered to contribute to leader effectiveness but the dynamics by which they have their effects have not been clarified. This study proposes that cooperative and competitive goal interdependence mediates the relationship between these values and outcomes. Working in organizations in Shanghai, China, 103 managers indicated their productivity and people values and 206 employees indicated their goa interdependence, leader effectiveness, and their commitment. Structural equation analysis suggested that productivity and people maintenance values affect goal interdependence which in turn results in leader effectiveness and employee commitment. Findings refine the theorizing by suggesting that leader values reduce competitive and independent goals but may not themselves strengthen cooperative goals. Results also suggest that leader values may directly induce employee commitment. The study's findings and previous research were interpreted as suggesting that productivity and people values coupled with cooperative goals provide a foundation for effective leadership.

\section{Introduction}

Leadership research has traditionally distinguished managers by their orientation toward production and people maintenance (Bass, 1990; Matsui et al., 1978; Misumi and Peterson, 1985; Stogdill and Coons, 1957). Findings overall suggest that leaders can be more effective when they integrate these orientations so that they value both production and people (Bass, 1990; Casimir and Keats, 1997). But research is needed to investigate the dynamics by which these values affect employees and leadership effectiveness. This study proposes that values have their impact by affecting the nature of the relationship between managers and employees (Tjosvold and Tsao, 1989). It uses the theory of cooperation and competition to examine the effects of leader values (Deutsch, 1973). It hypotheses that leader production and maintenance values develop cooperative, rather than competitive or independent, goals between managers and employees and that cooperative goals result in effective leadership and employee commitment.

Researchers have questioned whether values have much impact on actual leader behavior. Argyris and Schon $(1978,1996)$ have vigorously argued that leader espoused values have little effect on how managers actually work with employees. Managers typically espouse openness and mutual success but their actions indicate that they are committed to impersonality and trying to win. The wide discrepancy between espoused values and actual interaction results not only in ineffective leadership, but undermines feedback and learning. This study argues that leader values contribute to leader effectiveness to the extent they are supplemented with quality interpersonal relationships with employees.

\section{Leader production and maintenance}

Researchers have argued that leaders can be distinguished according to their orientation and values (Bass, 1990; Kerr and

Schrieshiem, 1974; Matsui et al., 1978; Misumi and Peterson, 1985; Stogdill and Coons, 1957). A productivity orientation shows that the leader wants employees to follow procedures and instructions so that they work productively. A people maintenance orientation demonstrates that the leader is supportive and concerned about employees as people. These dimensions can be independent so that leaders can be high or low on both orientations. Overall, research indicates that maintenance may be particularly useful for such outcomes as satisfaction and productivity for task accomplishment. However, it is often suggested that leaders should strive to be high on both people and production values to maximize constructive outcomes.

Characteristics of this research suggest qualifications to these implications. Studies have typically measured production and maintenance values through questionnaires administered to employees who indicate how they experience their managers. Employees though are not simply objective observers but use their own implicit theories to interpret and report on their leaders (Engle and Lord, 1996; Lord, 1985; Lord and Emrich, 2000). Employee responses reflect their experience and framework as well as their leader's values and behavior. Employees may not accurately perceive leader values or find them credible (Argyris and Schon, 1978, 1996).

Indeed, recent leadership research has largely ignored these values despite their long history (Hunt and Dodge, 2000). However, research on the effects of leader
The research register for this journal is available at http://www.emeraldinsight.com/researchregisters
The current issue and full text archive of this journal is available at http://w w w.emeraldinsight.com/0143-7739.htm 
Chun-hong Liu, Zi-you Yu and Dean Tjosvold

Production and people values: their impact on relationships and leader effectiveness in

China

Leadership \& Organization

Development Journal

23/3 [2002] 134-144 production and maintenance values on the leader relationship may help to make production and maintenance leadership research more current and useful (Brower et al., 2000). This study argues that production and maintenance values can affect the nature of the relationship between manager and employee, which in turn affects leader effectiveness and employee commitment. This study then can contribute to the research on mediators between the values and styles of leaders and their effects on employees (Congor et al., 2000; Dormann and Zapf, 1999; Foels et al., 2000; Jung and Avolio, 2000; Kirkpatrick and Locke, 1996; Pillai et al., 1999).

\section{Leader relationship}

Recent research has emphasized that managers can develop many different relationships with their employees and that the quality of these relationships can very much impact on leader success (Boyd and Taylor, 1998; Brower et al., 2000; Delugua, 1998; Gerstner and Day, 1997; Graen and Uhl-Bien, 1995; Howell and Hall-Merenda, 1999). When they develop high quality relationships, employees have been found to be more productive on the task and more willing to engage in organizationally useful activities.

This study uses the theory of cooperation and competition to examine the leader relationship. The basic premise of the theory of cooperation and competition is that the way goals are structured determines how individuals interact and their interaction pattern determines outcomes (Deutsch, 1949, 1973; Johnson and Johnson, 1989). Goals may be structured so that individuals promote the success of others or obstruct the success of others. When a situation is structured cooperatively, individuals' goal achievements are positively correlated; they perceive that they can reach their goals if, and only if, the others also reach their goals. When a situation is structured competitively, goal achievements are negatively correlated; each individual perceives that when one person achieves his or her goal, all others with whom he or she is competitively linked fail to achieve their goals.

Whether people understand the relationship among their individual goals is related cooperatively or competitively critically affects their expectations, interaction, and outcomes. In cooperation, people believe that as one person moves toward goal attainment, others move toward reaching their goals. They understand that others' goal attainment helps them; they can be successful together. With cooperative goals, people want each other to perform effectively, for such competence helps each person be successful. They interact in ways that promote mutual goals and resolve issues for mutual benefit.

In competition, people, believing that one's successful goal attainment makes others less likely to reach their goals, conclude that they are better off when others act ineffectively. When others are productive, they are less likely to succeed themselves. They pursue their interests at the expense of others. They want to "win" and have the other "lose".

By developing promotive interaction and open-minded discussion of views, cooperative goals have been found to facilitate quality solutions to problems, productivity, especially on complex tasks, and confidence in working together in the future (Alper et al., 1998; Johnson and Johnson, 1989;). Competitive goals have been found to frustrate interaction and result in fragmented relationships and low performance except on some simple tasks (Stanne et al., 1999). Independent goals have been found to have similar, though not as strong, effects as competitive goals.

This study empirically links leadership research with the theory of cooperation and competition. Cooperative goals are useful to characterize high quality leader relationships, whereas competitive and independent goals characterize low quality ones.

\section{Values, relationships, and outcomes}

Traditional research on leadership on production and maintenance and recent research on the leader relationship can be integrated. Leader values may be useful for they contribute to cooperative relationships. Valuing and working toward maintenance and production may help to convince employees and managers that they have cooperative goals.

Maintenance values can strengthen cooperative goals by demonstrating personal concern for employees. Deutsch (1973) argued that personal relationships and feeling of belonging develop cooperative goals, whereas impersonality and interpersonal distance foster competition. People see that their destinies are positively linked with those they know and regard positively whereas they are apt to believe that their goals are incompatible with those with whom they feel distant and removed (Gruenfeld et al., 1996; Lau and Murnighan, 1998). Similarly, feeling justly treated also is a powerful antecedent to cooperative goals (Deutsch, 1985). This argument suggests that maintenance values with their emphasis on sensitive, personal, and fair approaches to employees as 
Chun-hong Liu, Zi-you Yu and Dean Tjosvold

Production and people values: their impact on relationships and leader effectiveness in

China

Leadership \& Organization

Development Journal

23/3 [2002] 134-144 individuals would strengthen employee beliefs that they had cooperative goals with their leader. Low levels of maintenance communicate impersonality that fosters competitive and independent goals.

Leader productivity values can result in cooperative goals by emphasizing that the manager and employee have common, challenging tasks that they will work together to complete. Employees recognize that these leaders will provide the direction and structure so that their collaborative effort will be successful (Tjosvold et al., 1985). As they are optimistic that they can achieve and be successful together, they become committed to cooperative goals. Leaders with low levels of productivity emphasis may discourage employees by communicating that individual efforts will be unrewarded and poorly coordinated. Employees feel frustrated and develop competitive and independent goals with leaders who fail to focus on task completion.

\section{Hypotheses}

The overall model tested in this study emphasizes that leader values have their effects through the leader relationship (Figure 1). Leader values of productivity and maintenance affect the goal interdependence between manager and employees, which in turn affects outcomes. Based on the reasoning and research outlined above, it is hypothesized that:

H1. To the extent that leaders have productivity values, employees believe their goals with their leader are cooperative, but not competitive or independent.

H2. To the extent that leaders have maintenance values, employees believe their goals with their leader are cooperative, but not competitive or independent.

H3a. To the extent that employees and managers have cooperative goals, leaders are effective and employees are committed to their work.

$H 3 b$. To the extent that employees and managers have competitive and independent goals, leaders are ineffective and employees are uncommitted.

This study tests these hypotheses in organizations in China. Although research has focused on differences between the West and the East, it is useful to test theories developed in one culture to another (Bass, 1997; Morris et al., 1999). This study tests the universal aspirations of the theory of cooperation and competition.

This study also makes methodological contributions by having managers assess their values and employees indicate their goal interdependence and leader outcomes, making common method variance a less likely explanation of the results. This method was also thought to allow managers and employees to provide data that they were in a good position to report, that is, leaders reported on their values and employees reported on their interdependence and their leader's impact on them (Hooijberg and Choi, 2000).

\section{Method}

\section{Participants}

A sample of firms was recruited that is approximately representative of the

\section{Figure 1}

Hypothesized models

Leader Values $\quad$ Goal Independence $\quad$ Outcomes

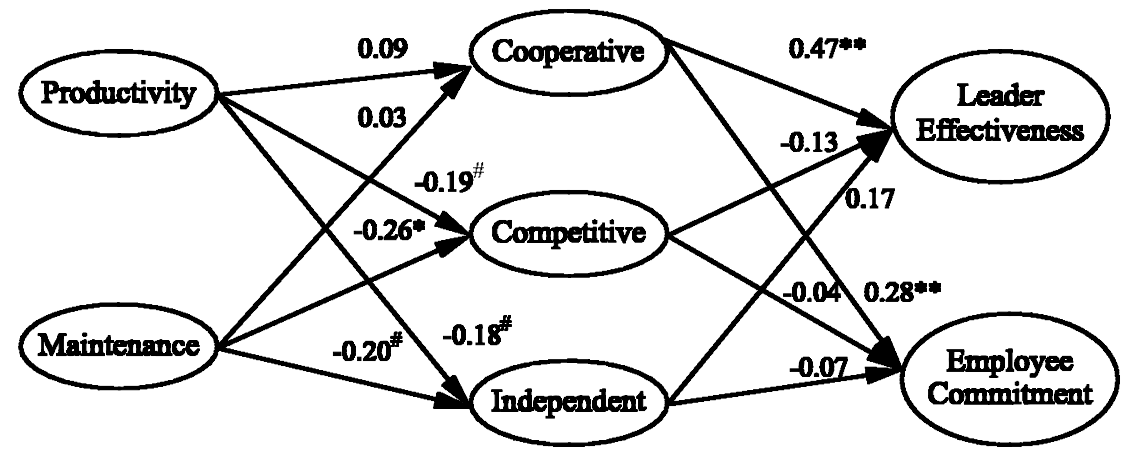


Chun-hong Liu, Zi-you Yu and Dean Tjosvold

Production and people values: their impact on relationships and leader effectiveness in

China

Leadership \& Organization

Development Journal

23/3 [2002] 134-144 industries in Shanghai, China: 47 firms are state-owned enterprises, 23 joint-stock companies, 24 China foreign joint venture, and nine private enterprises. A total of 22 firms are in manufacturing, three in construction, 18 in transportation, storage, postal and telecommunications, 12 in wholesale, retail and catering, 32 in banking and insurance, four in real estate, five in social services, four in education, culture, art, broadcasting, film and television, and one in government institutions, party and social organizations, and two in others.

Teams responsible for various tasks in these industries were recruited to participate in the study. In addition to the support of top and middle management for the study, confidentiality of responses was provided. To be included in the final sample, two employees who were part of the work group had to complete a survey and their manager had to complete a second survey. A total of 173 sets of questionnaires were distributed but 32 sets were not completed because of lack of time or interest in the study so 141 sets were collected. However, 21 sets were not complete because they lacked either the manager or one employee and seven more were rejected because questions were not completed. Thus, 103 sets of questionnaires were included in the data analysis. Average age of the team members was 31 and 60 per cent of the team members were males. Nearly all respondents had been in their teams for over six months.

Leader production and maintenance Scales for leader production and maintenance were taken from Misumi and Peterson (1985) and modified so that they reflected the values of the leader rather than the perceptions of employees. The six items about leadership style of a productivity orientation measured the emphasis on whether the employees followed procedures and instructions to work productively. A sample item for the leader production scale is "I want to make sure my employees know my instructions and orders" (see Appendix). Participants were asked to rate on a five-point scale ( 1 = strongly agree, $5=$ strongly disagree) their degree of agreement to the six statements.

The leader maintenance, with its emphasis on the leader's support and concern for employees, had seven items with similar anchors. A sample item is "I want my employees to talk freely with me". Both scales demonstrated acceptable reliability. The coefficient alpha for leader production was 0.70 and 0.83 for leader maintenance.

\section{Goal interdependence}

Scales for cooperative and competitive goal interdependence were developed from a previous questionnaire study conducted in North America (Alper et al., 1998). The five cooperative goals measured the emphasis on mutual goals, shared rewards, and common tasks. A sample item for the cooperative goal scale (cooperative) is "My boss and my goals go together". Participants were asked to rate on a five-point scale $(1=$ strongly agree, $5=$ strongly disagree) their degree of agreement to the five statements.

The competitive goal scale (competitive) had five items with similar anchors to measure the emphasis on incompatible goals and rewards. A sample item is "My boss and I have a win-lose relationship". The independent goal scale (independent) had four items with similar anchors to measure the emphasis on incompatible goals and rewards. A sample item is "My boss and I work for our own interests". Coefficient alphas for the cooperative, competitive and independent goal scales were $0.69,0.85$, and 0.73 respectively.

\section{Leader effectiveness and employee commitment}

Scales for expectation for leader effectiveness and employee commitment were developed from previous research. Leader effectiveness measured the extent to which employees believed that their manager was successful as a leader (Delugua, 1998). A sample item for this scale is "I am satisfied with my manager's overall effectiveness as a leader". Participants were asked to rate on a five-point scale ( 1 = strongly agree, $5=$ strongly disagree) their degree of agreement to six statements. The scale had a Cronbach alpha of 0.87 .

Employee commitment measured the extent to which employees described themselves as involved and motivated in their own assignments (Tjosvold et al., 1998). A sample item is "I feel highly committed to the goals of my work". Participants were asked to rate on a five-point scale ( $1=$ strongly agree, $7=$ strongly disagree) their degree of agreement to four statements. The scale had a Cronbach alpha of 0.80 .

The questionnaires originally written in English were translated into Chinese by two members of the research team who are native Chinese. To ensure conceptual consistency, the questionnaires were back translated into English to check for possible deviation (Brislin, 1970). The questionnaires were pre-tested to make sure that respondents clearly understood every 
Chun-hong Liu, Zi-you Yu and Dean Tjosvold

Production and people values: their impact on relationships and leader effectiveness in

China

Leadership \& Organization

Development Journal

23/3 [2002] 134-144 phrase, concept, and question. To prevent and eliminate potential concern for being involved in evaluating others, participants were assured that their responses would be held totally confidential.

\section{Analysis}

\section{Data aggregation}

We aggregated team members' ratings of cooperative goal, competitive goal, independent goal, leader effectiveness, and employee commitment to the team level in the analyses. The fundamental reason was that the hypotheses identified the unit of analysis as the group.

However, the aggregation required that the perceptions of team members within a team were reasonably homogeneous. We used James et al.'s (1984) procedure to estimate the inter-rater reliability of members within each team for each of the five individual-level variables. James et al.'s $r_{\mathrm{WG}(\mathrm{J})}$ index was used as an estimate of inter-rater reliability because each of the five variables was measured by multiple items. Two indicators showed that the ratings among members in each group were quite homogeneous:

1 The median $r_{\mathrm{WG}(J)}$ for the five variables across the 103 teams was $0.96,0.94,0.94$, 0.90 and 0.97 respectively.

2 George and Bettenhausen (1990) argued that $r_{\mathrm{WG}(J)}$ which was greater than or equal to 0.70 could be considered as indicators of good agreement within group.

Out of the 103 teams, the percentages of teams with $r_{\mathrm{WG}(\mathrm{J})}$ greater than or equal to 0.70 across the five variables were 0.94, 0.89, 0.90, 0.84 and 0.96 respectively. We therefore concluded that the within-team ratings were homogeneous enough to be aggregated to the team level. Individual team members' ratings were aggregated to the team level and the data merged with managerial ratings of team innovation and recovering. The final sample size of the merged data file was 103 teams.

\section{Hypotheses testing}

Correlational analyses were used as an initial test of the hypotheses. Structural equation analyses were used to test the proposed model that goal independence mediates the relationship between productivity and people maintenance values and the outcomes of leader effectiveness and employee commitment.

To more vigorously test the theory, structural equation analysis with the EQS for Macintosh program was used to examine the underlying causal structure between values, goal independence, and outcomes (Bentler and $\mathrm{Wu}, 1995)$. This analysis involved only the structural model, not the measurement model.

Research was used to propose the model that goal independence mediates the relationship between productivity and people maintenance values and outcomes of leader effectiveness and employees commitment. The mediating effects model suggested by the theory implies that there should be no direct effects between productivity and people maintenance values and outcomes, that is, goal independence mediates the relationship between values and outcomes.

A nested model test commonly adopted in causal model analysis was used where the mediating effects model was compared to the direct effects model. The direct effects model posited that production and maintenance values impact on outcomes directly.

\section{Results}

Zero-order correlations provide an initial examination of the hypotheses linking leader productivity and maintenance values, goal interdependence, leader effectiveness, and employee commitment (Table I). Results provide partial support for $H 1$ that productivity values affect goal interdependence. Productivity values were negatively correlated with competitive goals $(-0.31, p<0.01)$ and with independent goals $(-0.28, p<0.01)$. However, productivity was not significantly related to cooperative goals (0.10).

Similarly, results provide partial support for $\mathrm{H} 2$ that maintenance values affect goal interdependence Maintenance was negatively correlated with competitive goals $(-0.35, p<0.01)$ and with independent goals $(-0.29, p<0.01)$, but was not significantly related to cooperative goals (0.08).

The correlational results also provide partial support for $H 3$ that employees who believe their goals with leaders are cooperative and not competitive or independent conclude that their leader is effective and are committed to their work. Consistent with $H 3 a$, employees with cooperative goals indicated that their leader was effective $(0.47, p<0.01)$ and that they were committed $(0.31, p<0.01)$. However, results do not support $H 3 b$ that employees with competitive goals would conclude that their leader is ineffective $(-0.11, \mathrm{~ns})$ and feel uncommitted $(-0.16$, ns) or that employees with independent goals would believe their 
Chun-hong Liu, Zi-you Yu and Dean Tjosvold

Production and people values: their impact on relationships and leader effectiveness in

China

Leadership \& Organization

Development Journal

23/3 [2002] 134-144 leader is ineffective $(-0.03, \mathrm{~ns})$ and be uncommitted ( -0.16 , ns).

Structural equation analyses through EQS were used to explore the relationship between values, goals, and outcomes. Table II shows the path estimates for the model tested in this study. The mediating effects and the direct effects models were compared. The $\chi^{2}$ of the mediating effects model was $\chi^{2}=10.26$ (d.f. $=4, p<0.01$ ) and the $\chi^{2}$ of the direct effects model was 157.37 (d.f. $=15, p<0.01$ ). The difference of $\chi^{2}$ between the mediating model and the direct effects model was significant $\left(\chi^{2}\right.$ difference $\left.=147.11\right)$, indicating that omission of the mediating effects of goal independence significantly deteriorated the mediating model. Results of the causal model comparison suggest that the mediating effects model be accepted.

The path coefficients of the accepted model help to explore the findings more specifically (Figure 1). Results indicate that productivity values have marginally significant negative effects on competitive goals $(\beta=-0.19, p<0.10)$ and independent goals $(\beta=-0.18, p<0.10)$, and maintenance values also have significant negative effects on competitive goals $(\beta=-0.26, p<0.01)$ and marginally significant negative effects on independent goals $(\beta=-0.20, p<0.10)$.

Cooperative goals had a significant positive effect on leader effectiveness $(\beta=0.47, p<0.01)$ and job

Table I

Correlations among variables at the team level

\begin{tabular}{|c|c|c|c|c|c|c|c|c|c|}
\hline & Mean & $\begin{array}{c}\text { Std } \\
\text { deviation }\end{array}$ & Productivity & Maintenance & Cooperative & Competitive & Independent & $\begin{array}{c}\text { Leader } \\
\text { effectiveness }\end{array}$ & $\begin{array}{c}\text { Employee } \\
\text { commitment }\end{array}$ \\
\hline Productivity & 1.78 & 0.50 & $(0.70)$ & & & & & & \\
\hline Maintenance & 1.70 & 0.56 & $0.48 * *$ & $(0.83)$ & & & & & \\
\hline Cooperative & 2.23 & 0.56 & 0.10 & 0.08 & $(0.69)$ & & & & \\
\hline Competitive & 3.44 & 0.72 & $-0.31 * *$ & $-0.35 * *$ & $-0.25 *$ & $(0.85)$ & & & \\
\hline $\begin{array}{l}\text { Independent } \\
\text { Leader }\end{array}$ & 3.30 & 0.63 & $-0.28 * *$ & $-0.29 * *$ & $-0.20 *$ & $0.80 * *$ & $(0.73)$ & & \\
\hline $\begin{array}{l}\text { effectiveness } \\
\text { Employee }\end{array}$ & 2.50 & 0.69 & 0.12 & 0.06 & $0.47 * *$ & -0.11 & -0.03 & $(0.87)$ & \\
\hline $\begin{array}{l}\text { commitment } \\
\text { Notes: } \\
n=103 \\
\text { Values in paren } \\
* * p<0.01 ; * p\end{array}$ & $\begin{array}{l}\text { ses ar } \\
05 .\end{array}$ & liability ( & fficient alpha & estimates & $0.31 * *$ & -0.16 & -0.16 & $0.44 * *$ & $(0.80)$ \\
\hline
\end{tabular}

Table II

Parameter estimates for structural model

\begin{tabular}{|c|c|c|c|c|c|}
\hline \multicolumn{3}{|c|}{ Mediating effects model } & \multicolumn{3}{|c|}{ Direct effects model } \\
\hline Path from & Path to & Path coeffiicient & Path from & Path to & Path coefficient \\
\hline Productivity & Cooperative & 0.09 & Productivity & Leader effectiveness & 0.12 \\
\hline Productivity & Competitive & $-0.19 *$ & Productivity & Employee commitment & $0.29 * * *$ \\
\hline Productivity & Independent & $-0.18 *$ & Maintenance & Leader effectiveness & 0.01 \\
\hline Maintenance & Cooperative & 0.03 & Maintenance & Employee commitment & 0.07 \\
\hline Maintenance & Competitive & $-0.26 * *$ & & & \\
\hline Maintenance & Independent & $-0.20 *$ & & & \\
\hline Cooperative & Leader effectiveness & $0.47 * * *$ & & & \\
\hline Cooperative & Employee commitment & $0.28 * * *$ & & & \\
\hline Competitive & Leader effectiveness & -0.13 & & & \\
\hline Competitive & Employee commitment & -0.04 & & & \\
\hline Independent & Leader effectiveness & 0.17 & & & \\
\hline Independent & Employee commitment & -0.07 & & & \\
\hline Model $\chi^{2}$ & Model $\chi^{2}$ & 10.26 & Model $\chi^{2}$ & Model $\chi^{2}$ & 152.37 \\
\hline d.f. & d.f. & 4 & d.f. & d.f. & 15 \\
\hline BBNFI & BBNFI & 0.95 & BBNFI & BBNFI & 0.29 \\
\hline CFI & $\mathrm{CFI}$ & 0.97 & CFI & $\mathrm{CFI}$ & 0.29 \\
\hline \multicolumn{6}{|c|}{$\begin{array}{l}\text { Notes: } \\
* * * p<0.01 ; * * p<0.05 ; * p<0.10\end{array}$} \\
\hline
\end{tabular}


Chun-hong Liu, Zi-you Yu and Dean Tjosvold

Production and people values: their impact on relationships and leader effectiveness in

China

Leadership \& Organization

Development Journal

23/3 [2002] 134-144 commitment ( $\beta=0.28, p<0.01)$. Competitive goals had a negative effect on leader effectiveness $(\beta=-0.13)$ and job commitment $(\beta=-0.04)$, and independent goals also had a negative effect on job commitment ( $\beta=-0.07)$, but these relationships were not statistically significant.

With regard to model fit, the mediating effects model had a model chi-square of 10.26 and four degrees of freedom. The CFI and TLI for the model were 0.95 and 0.97 respectively. Both fit indices were considered as indicating good model fit, given the usually accepted critical value of 0.90 (Bentler and Bonnett, 1980).

\section{Discussion}

Results support the overall logic that production and people values impact on leadership effectiveness through their effects on the manager-employee relationships. Leaders's own descriptions of their commitment to productivity and people were found to be related to employee reports of their goal interdependence with their leaders. These goal interdependences in turn were found to be related to:

- leader effectiveness; and

- employee commitment.

However, the links between values, goal interdependence, and outcomes were more complex than hypothesized. Productivity and maintenance values appear to have their effects by reducing competitive and independent goals, not by building cooperative ones. These values did not have statistically significant relationships with cooperative goal interdependence, but were, as hypothesized, found to have significant negative relationships with competitive and independent goals. As hypothesized, cooperative goals did predict to leader effectiveness and employee commitment but, contrary to the hypotheses, competitive and independent goals were not significantly negatively related to these outcomes.

Employees appear to have considered leader values on productivity and people reasons to reduce their concerns that their leaders were trying to outdo and win interpersonally. They were less suspicious of leaders who espoused productivity and people values. However, this reduced suspicion was not enough to strengthen cooperative goals significantly.

Employees may often be skeptical of the espoused values of their managers (Argyris and Schon, 1978, 1996; Hogan et al., 1994). Perhaps employees want more tangible evidence that they had cooperative goals than leaders' own commitment to productivity and people values. They may want to experience leaders' team building actions, such as developing common goals and sharing rewards for joint success, in order to conclude that they have strong cooperative goals with the leader. Rather than relying on leaders' espousing maintenance, employees may want to experience a personal relationship with their manager before they conclude their goals are highly cooperative. Future research is needed to investigate this speculation.

Evidence also suggests that values may have a different route to affecting employee commitment than leader effectiveness. Whereas values were not related directly to leader effectiveness, leader values were significantly correlated with employee commitment. It may be that the espoused values of leaders themselves can be directly useful for developing employee commitment. Employees whose leaders are committed to productivity and to people may be able to find their work more meaningful and develop commitment to it. However, these values do not by themselves result in their manager leading effectively. Research is needed to explore this reasoning.

Recent research has emphasized that quality relationships are a foundation for leader effectiveness (Boyd and Taylor, 1998; Brower et al., 2000; Delugua, 1998; Gerstner and Day, 1997; Graen and Uhl-Bien, 1995; Howell and Hall-Merenda, 1999). Results support this theorizing and suggest that cooperative goals are a useful way of understanding these quality relationships. When employees in this study believed they had cooperative goals with their leaders, they were likely to conclude that their leader is effective and to feel committed to their work.

The theory of cooperation and competition, although developed in the West, proved useful for understanding values and leadership dynamics in China (Deutsch, 1973). Leader values were found to be related to goal interdependence and goal interdependence in turn to leader effectiveness and outcomes. The research approach of identifying conditions that impact on organizational dynamics and outcomes in China with a theory with universal aspirations may be a viable addition to the traditional alternatives of comparing samples from different cultures and exploring a cultural variable with an indigenous theory (Bass, 1997; Leung, 1997). 
Chun-hong Liu, Zi-you Yu and Dean Tjosvold

Production and people values: their impact on relationships and leader effectiveness in China

Leadership \& Organization Development Journa 23/3 [2002] 134-144
The research approach used in this study can both probe general theories and improve understanding of organizational dynamics in non-Western cultures.

\section{Limitations}

The sample and operations, of course, limit the results of this study. The data are self-reported and subject to biases, and may not accurately describe the relationships, although recent research suggests that selfreported data are not as limited as commonly expected (Spector, 1992). These data are also correlational and do not provide direct evidence of causal links between values, goal interdependence, and outcomes. However, managers completed measures of values and their employees completed measures of goal interdependence, leader effectiveness, and employee commitment. Developing different sources for the independent and dependent measures should reduce the possibilities of the same source method as an alternative explanation of the results.

Spector and Brannick (1995) have argued that the most effective way to overcome recall and other methodological weaknesses is to test ideas with different methods. It would be desirable to provide direct experimental verification of the role of productivity and people values on leadership effectiveness in East Asian organizational settings.

\section{Practical implications}

In addition to developing theoretical understanding, the hypotheses, if they can continue to be supported, have important practical implications for developing leadership, especially in China and perhaps other collectivist cultures. Results further document that leader values on productivity and people values can be useful for building employee commitment. However, values need to be supplemented with cooperative goals between managers and leaders if they are to result in effective leadership. Managers and employees can together develop common tasks, integrated roles, and shared reward distributions that build cooperative goals (Hanlon et al., 1994; Tjosvold and Tjosvold, 1995).

This study contributes to growing recognition of the importance of examining mediators between the values and styles of leaders and their effects on employees (Congor et al., 2000; Dormann and Zapf, 1999; Foels et al., 2000; Jung and Avolio, 2000; Kirkpatrick and Locke, 1996; Pillai et al., 1999). Specifically, it provides an empirical examination of the relationship dynamics by which leader values affect leader effectiveness and employee commitment. Leader commitment to productivity and people values was found to predict directly to employee commitment. However, leader values appear to have their effects on leader effectiveness to the extent that they can affect the relationship between manager and employee.

Results suggest that productivity and people values, though they reduce competitive and independent goals, are insufficient to develop cooperative goals between managers and employees.

Production and people values along with cooperative goals appear to be important bases for developing effective leadership in China.

\section{References}

Alper, S., Tjosvold, D. and Law, S.A. (1998), "Interdependence and controversy in group decision making: antecedents to effective self-managing teams", Organizational Behavior and Human Decision Processes, Vol. 74, pp. 33-52.

Arygris, C. and Schon, D.A. (1978), Organizational Learning: A Theory of Action Perspective, Addison-Wesley, Reading, MA.

Arygris, C. and Schon, D.A. (1996), Organizational Learning II: Theory, Method, and Practice, Addison-Wesley, Reading, MA.

Bass, B.M. (1990), Bass and Stogdill's Handbook of Leadership, 3rd ed., The Free Press, New York, NY.

Bass, B.M. (1997), "Does the transactionaltransformational leadership paradigm transcend organizational and national boundaries?", American Psychologist, Vol. 52, pp. 130-9.

Bentler, P.M. and Bonnett, D.G. (1980), "Significance tests and goodness of fit in the analysis of covariance structure", Psychological Bulletin, Vol. 88, pp. 588-606.

Bentler, P.M. and Wu, E.J.C. (1995), EQS for Macintosh User's Guide, Multivariate Software, Encino, CA.

Boyd, N.G. and Taylor, R.R. (1998), “A developmental approach to the examination of friendship in leader-follower relationships”, Leadership Quarterly, Vol. 9, pp. 1-25.

Brislin, R.W. (1970), "Back-translation for cross-cultural research", Journal of Cross-cultural Psychology, Vol. 1, pp. 185-216.

Brower, H.H., Schoorman, F.D. and Tan, H.H. (2000), "A model of relational leadership: the integration of trust and leader-member exchange”, Leadership Quarterly, Vol. 11, pp. 227-50.

Casimir, G. and Keats, D. (1997), "The effects of work environment and in-group membership on the leadership preferences of AngloAustralians and Chinese Australians", 
Chun-hong Liu, Zi-you Yu and Dean Tjosvold

Production and people values: their impact on relationships and leader effectiveness in

China

Leadership \& Organization

Development Journal

23/3 [2002] 134-144
Journal of Cross-Cultural Psychology, Vol. 28, pp. 436-57.

Congor, J.A., Kanungo, R. and Menon, S.T. (2000), "Charismatic leadership and follower effects”, Journal of Organizational Behavior, Vol. 21, pp. 747-68.

Delugua, R.J. (1998), "Leader-member exchange quality and effectiveness ratings", Group and Organization Management, Vol. 23, pp. 189-216

Deutsch, M. (1949), "A theory of cooperation and competition”, Human Relations, Vol. 2, pp. 129-52.

Deutsch, M. (1973), The Resolution of Conflict, Yale University Press, New Haven, CT.

Deutsch, M. (1985), Distributive Justice: A Socialpsychological Perspective, Yale University Press, New Haven, CT.

Dormann, C. and Zapf, D. (1999), "Social support, social stresssors at work, and depressive symptoms: testing for main and moderating effects with structural equations in a threewave longitudinal study", Journal of Applied Psychology, Vol. 84, pp. 680-94.

Engle, E.M and Lord, R.G. (1996), "Implicit theories, self-schemas, and leader-member exchange", Academy of Managment Journal, Vol. 40, pp. 988-1010.

Foels, R., Driskell, J.E., Mullen, B. and Salas, E. (2000), "The effects of democratic leadership on group member satisfaction”, Small Group Research, Vol. 31, pp. 676-701.

George, J.M. and Bettenhausen, K. (1990), "Understanding prosaic behavior, sales performance, and turnover: a group-level analysis in a service context", Journal of Applied Psychology, Vol. 75, pp. 698-709.

Gerstner, C.R. and Day, D.V. (1997), "Metaanalytic review of leader-member exchange theory: correlates and construct issues", Journal of Applied Psychology, Vol. 82, pp. 827-44.

Graen, G.B., and Uhl-Bien, M. (1995), "Relationship-based approach to leadership: development of leader-member exchange (LMX) theory of leadership over 25 years: applying a multi-level multi-domain perspective”, Leadership Quarterly, Vol. 6, pp. 219-47.

Gruenfeld, D.H., Mannix, E.A., Williams, K.Y. and Neale, M.A. (1996), "Group composition and decision making: how member familiarity and information distribution affect process and performance", Organizational Behavior and Human Decision Processes, Vol. 67, pp. 1-15.

Hanlon, S.C., Meyer, D.C. and Taylor, R.R. (1994), "Consequences of gainshairing: a field experiment revisited", Group and Organizational Management, Vol. 19, pp. 87-111.

Hogan, R., Curphy, G.J. and Hogan, J. (1994), "What we know about leadership: effectiveness and personality", American Psychologist, Vol. 49, pp. 493-504.
Hooijberg, H. and Choi, J. (2000), "Which leadership roles matter to whom? An examination of rater effects on perceptions of effectiveness", Leadership Quarterly, Vol. 11, pp. 341-64.

Howell, J.M. and Hall-Merenda, K.E. (1999), "The ties that bind: the impact of leader-member exchange, transformational and transactional leadership, and distance on predicting follower performance", Journal of Applied Psychology, Vol. 84, pp. 680-94.

Hunt, J.G. and Dodge, G.E. (2000), "Leadership déjà vu all over again”, Leadership Quarterly, Vol. 11, pp. 435-58.

James, L.R., Demaree, R.G. and Wolf, G. (1984), "Estimating within-group interrater reliability with and without response bias", Journal of Applied Psychology, Vol. 69, pp. 85-98.

Johnson, D.W. and Johnson, R.T. (1989), Cooperation and Competition: Theory and Research, Interaction Book Company, Edina, MN.

Jung, D.I. and Avolio, B.J. (2000), “Opening the black box: an experimental investigation of the mediating effects of trust and value congruence on transformational and transactional leadership", Journal of Organizational Behavior, Vol. 21, pp. 949-64.

Kerr, S. and Schrieshiem, C.A. (1974), "Consideration, initiating structure, and organizational criteria: an update of Korman's 1966 review”, Personnel Psychology, Vol. 27, pp. 555-68.

Kirkpatrick, S.A. and Locke. E.A. (1996), “Direct and infirect effects of the core charismatic leadership components on performance and attitudes", Journal of Applied Psychology, Vol. 81, pp. 36-51.

Lau, D.C. and Murnighan, J.K. (1998), "Demographic diversity and faultlines: the compositional dynamics of organizational groups", Academy of Management Review, Vol. 23, pp. 325-40.

Leung, K. (1997), "Negotiation and reward allocations across cultures", in Earley, P.C. and Erez, M. (Eds), New Perspectives on International Industrial/Organizational Psychology, Jossey-Bass, San Francisco, CA, pp. 640-75.

Lord, R.G. (1985), “An information processing approach to social perceptions, leadership and behavioral measurement in organizations”, in Cummings, L.L. and Staw, B.M. (Eds), Research in Organizational Behavior, Volume 7, JAI Press, Greenwich, CT, pp. 87-128.

Lord, R.G. and Emrich, C.G. (2000), "Thinking outside the box by looking inside the box: extending the cognitive revolution in leadership research", Leadership Quarterly, Vol. 11, pp. 551-79.

Matsui, T., Ohtsuka, Y. and Kikuchi, A. (1978), "Consideration and structure behaviour as reflections of supervisory interpersonal 
Chun-hong Liu, Zi-you Yu and Dean Tjosvold

Production and people values: their impact on relationships and leader effectiveness in

China

Leadership \& Organization

Development Journal

23/3 [2002] 134-144 values", Journal of Applied Psychology, Vol. 63 No. 2, pp. 259-62.

Misumi, J. and Peterson, M.F. (1985), “The performance-maintenance (PM) theory of leadership: review of a Japanese research program”, Administrative Science Quarterly, Vol. 30, pp. 198-223.

Morris, M.W., Leung, K., Ames, D. and Lickel, B. (1999), "Views from inside and outside: integrating emic and etic insights about culture and justice judgment" Academy of Management Review, Vol. 24, pp. 781-96.

Pillai, R., Schriesheim, C.A. and Williams, E.S. (1999), "Fairness perceptions and trust as mediators for transformational and transactional leadership: a two-sample study”, Journal of Management, Vol. 25, pp. 897-933.

Spector, P.E. (1992), “A consideration of the validity and meaning of self-report measures of job conditions", in Cooper, C.L. and Robertson, I.T. (Eds), International Review of Industrial and Organizational Psychology, Wiley, Chichester, pp. 123-51.

Spector, P.E. and Brannick, M.T. (1995), "The nature and effects of method variance in organizational research", in Cooper, C.L. and Robertson, I.T. (Eds), International Review of Industrial and Organizational Psychology, Wiley, Chichester, pp. 249-74.

Stanne, M.B., Johnson, D.W. and Johnson, R.T. (1999), "Does competition enhance or inhibit motor performance: a meta-analysis", Psychological Bulletin, Vol. 125, pp. 133-54.

Stogdill, R.A. and Coons, A.E. (1957), Leader Behavior: Its Description and Measurement, Bureau of Business Research, Ohio State University, Columbus, $\mathrm{OH}$.

Tjosvold, D. and Tjosvold, M.M. (1995),

"Cooperation theory, constructive controversy, and effectiveness: learning from crises”, in Guzzo, R.A. and Salas, E. (Eds), Team Effectiveness and Decision Making in Organizations, Jossey-Bass, San Francisco. CA, pp. 79-112.

Tjosvold, D. and Tsao, Y. (1989), "Productive organizational collaboration: the role of values and cooperative goals", Journal of Organizational Behavior, Vol. 10, pp. 189-95.

Tjosvold, D., Andrews, I.R. and Jones, H. (1985), "Alternative ways leaders can use authority", Canadian Journal of Administrative Sciences, Vol. 2, pp. 307-17.

Tjosvold, D., Sasaki, S. and Moy, J. (1998), "Developing commitment in Japanese organizations in Hong Kong: interdependence, interaction, relationship and productivity”, Small Group Research, Vol. 29, pp. 560-82.

\section{Further reading}

Chen, C.C., Chen, X. and Meindl, J.R. (1998), "How can cooperation be fostered? The cultural effects of individualism-collectivism",
Academy of Management Review, Vol. 23, pp. 285-304.

Deutsch, M. (1980), "Fifty years of conflict", in Festinger, L. (Ed.), Retrospections on Social Psychology, Oxford University Press, New York, NY, pp. 46-77.

\section{Appendix}

\section{Leadership values}

1 Productivity:

- It is important that my employees follow regulations.

- I want to make sure my employees know my instructions and orders.

- It is important that employees know the deadlines I have set for their work.

- I want employees to work at their maximum capacity.

- My employees are to give me reports on the progress of their work.

- I want to give my employees specific instructions for how to achieve their goals.

2 Maintenance:

- I want my employees to talk freely with me.

- I believe it is important for me to communicate support to my employees.

- I want to show concern for my employees' personal concerns.

- It is important that my employees trust me.

- I want to recognize publicly the accomplishments of my employees.

- I want my employees to know that I am concerned about their future promotions, pay raises, and other benefits.

- My treating my employees fairly is very important to me.

\section{Goal interdependence}

1 Cooperation:

- My boss and my goals go together.

- When my boss and I work together, we usually have common goals.

- My boss shows as much concern for what he wants to accomplish as to what I want to accomplish.

- My boss and I help each other to achieve our objectives.

- My boss and I want each other to succeed.

2 Competition:

- What helps me, gets in my boss's way.

- My boss and I have a win-lose relationship.

- My goals are incompatible with my boss's goals. 
Chun-hong Liu, Zi-you Yu and Dean Tjosvold

Production and people values: their impact on relationships and leader effectiveness in China

Leadership \& Organization Development Journa 23/3 [2002] 134-144

This work has been supported by the Research Grants Council of the Hong Kong Special Administrative Region, China (Project No: LC3004/98H) to the first author.
- I structure things in ways that favor my goals rather than my boss's.

3 Independence:

- I give high priority to things I want to accomplish, and low priority to things my boss wants to accomplish. (I care about mine, but not my boss's accomplishment.)

- My boss and I each "do his own thing".

- My boss likes to be successful through his own work.

- My boss and I work for our own interests.

- My success is unrelated to my boss.

Leader effectiveness:

- My manager performs the roles as supervisor the way I would like it to be.
- My manager meets my expectations in his responsibilities as a supervisor.

- If I had my way, I think I would change the manner in which my manager performs as a supervisor (reverse).

- I am satisfied with my manager's overall effectiveness as a leader.

\section{Employee commitment}

- Generally speaking, I am very satisfied with my work.

- I feel a strong commitment to my work.

- I feel highly committed to the goals of my work.

- All things considered, I am highly pleased with my job. 